\title{
EDITORIAL
}

\section{Endowment FMUSP: nova identidade visual e tecnologia na captação de recursos}

\author{
Endowment FMUSP: new visual ID and embedded technology \\ to collect donations
}

\begin{abstract}
Nilo Arthur Bezerra Martins ${ }^{1}$, Gustavo Rosa Gameiro², João Martins Cortez Filho $^{1}$, Henrique Tibucheski dos Santos ${ }^{1}$, Tiago Guitián dos Reis ${ }^{3}$
\end{abstract}

\begin{abstract}
Deixando mais de 500 mil vítimas só em nosso país, a pandemia de COVID-19 pôs em xeque os sistemas de saúde do mundo inteiro. Nesse contexto, os olhares se voltaram também à sustentabilidade e à filantropia. Precisa-se de meios alternativos para complementar o financiamento da saúde e, por conseguinte, da educação médica no Brasil.

Endowments são ferramentas estratégicas no âmbito da bem consolidada cultura de filantropia norte-americana. Tais modelos tornaram-se tão relevantes que figuram, hoje, como a principal fonte de recursos para grandes universidades da Ivy League, como Harvard, Yale e Stanford. No último século, os endowments se mostraram uma forma valiosa de aplicação financeira, em especial os que se baseiam no modelo de Yale, proposto por David Swensen e nascido no fundo patrimonial de Yale. Tal modelo busca fazer uma alocação de capital em classes de ativos de retorno histórico elevado e de baixa correlação entre essas classes. É um modelo que faz sentido para endowments, que possuem Capital perpétuo e podem investir com visão de longo prazo.

A Faculdade de Medicina da Universidade de São Paulo (FMUSP), guiando-se pelos princípios do já consolidado Modelo de Yale, e espelhando-se em exemplos bem sucedidos, formou um Endowment pioneiro dentre as escolas médicas brasileiras: o Fundo Medicina. A associação, independente e sem fins lucrativos, gerencia o fundo patrimonial oficial da FMUSP, constituído por doações de pessoas físicas e jurídicas.
\end{abstract}

\footnotetext{
1. Fundo Medicina - Endowment FMUSP, Faculdade de Medicina da Universidade de São Paulo. ORCID: Martins NAB - https://orcid.org/0000-00034179-2756; Cortez Filho JC - https://orcid.org/0000-0001-6430-0158; Santos HT - https://orcid.org/0000-0001-7369-8030. Email: nilo.arthur@fm.usp. br, joao.mcfilho@fm.usp.br, henrique.tibucheski@fm.usp.br.

2. Faculdade de Medicina da Universidade de São Paulo - FMUSP, Centro de Desenvolvimento de Educação Médica - CEDEM. Departamento de Oftalmologia e Ciências Visuais, Escola Paulista de Mediicna - EPM - UNIFESP. https://orcid.org/0000-0002-0400-8013. Email: gustavo.gameiro@ fm.usp.br.

3. Suno. https://orcid.org/0000-0002-4283-878X. Email: tiago.reis@sunoresearch.com.br
} 
A consolidação do Fundo Medicina está alinhada com o atual movimento de criação de Endowments no Brasil, impulsionado recentemente pela sanção da Lei de Fundos Patrimoniais (Lei 13.800/19). Dessarte, variados Endowments foram legitimados, como o da Escola Politécnica da USP (Amigos da Poli), o da UNICAMP e o do curso de Direito da FGV. Em comum, apresentam o grande desafio de aproximar os alumni da alma-máter e incentivar a cultura de filantropia acadêmica em nosso país.

A conhecida sustentabilidade de um fundo patrimonial deve-se a um dos princípios universais a qualquer associação do tipo: os recursos arrecadados jamais são consumidos, mas sim aplicados no mercado financeiro com a ajuda de profissionais do setor. Assim, apenas os rendimentos de tais investimentos retornam à FMUSP, garantindo a perenidade do montante principal.

Dessa forma, por meio dessa ferramenta filantrópica, os doadores podem deixar um legado permanente - mesmo que doem apenas uma vez -, o qual irá viabilizar projetos inovadores de alunos, professores e agremiações da Faculdade, contribuindo diretamente para o vanguardismo da Casa de Arnaldo. As colaborações ajudam na implementação de novas ferramentas pedagógicas, impulsionam a formação de novos talentos, a melhoria de laboratórios de pesquisa, estimulam a produção científica e a inovação, e ajudam no desenvolvimento de atividades esportivas e de trabalho voluntário.

Nos anos de 2020 e 2021, o Fundo passou por uma substancial reforma jurídica, que permitirá que os processos internos de sua administração ocorram de forma mais transparente e menos burocrática. Agora, o Fundo Medicina conta com a colaboração de diversas pessoas compondo sua estrutura administrativa, entre alunos, professores, médicos e profissionais do mercado financeiro, todos trabalhando de maneira voluntária, em prol do desenvolvimento da cultura de filantropia no ecossistema da Faculdade de Medicina da USP. Após anos de aprendizado com os obstáculos inerentes a um projeto pioneiro no Brasil, o Fundo se apresenta ao público em uma fase mais madura, com um arcabouço jurídico melhor fundamentado e um capital humano valioso engajado no projeto.

Tendo a tecnologia como aliada, o Endowment FMUSP desenvolveu um novo website a fim de divulgar suas atividades e viabilizar contribuições feitas pela internet por meio do seu Portal de Doações. Tais plataformas são essenciais para o crescimento do Fundo Medicina pois expandem seu alcance para angariar potenciais doadores. Nesse novo Portal, o doador tem controle total sobre seus aportes e pode contribuir com qualquer valor, de maneira simples e rápida, selecionando entre diversas formas disponíveis para pagamento.

Doar para o Fundo Medicina é a oportunidade perfeita para deixar a sua marca e gerar valor compartilhado para sociedade. O conceito de give it back é a essência da cultura de filantropia acadêmica que desejamos impulsionar: retorne à alma-mater um pouco de tudo aquilo que ela the ajudou a conquistar na vida com uma formação gratuita e de excelência. 